\title{
Brain tumours in Sweden 1996: care and costs
}

\author{
P Blomqvist, J Lycke, P Strang, H Törnqvist, A Ekbom
}

Department of

Medical Epidemiology,

Karolinska Institutet,

Stockholm, Sweden

P Blomqvist

A Ekbom

Institute of Clinical

Neuroscience,

Department of

Neurology,

Gothenburg

University,

Sahlgrenska University

Hospital, Gothenburg,

Sweden

J Lycke

Palliative Research

Unit, Vrinnevi

Hospital, Linköping

University,

Norrköping, Sweden

P Strang

The Swedish Institute for Development of the Health Services, Stockholm, Sweden

$\mathrm{H}$ Törnqvist

Correspondence to: Dr P Blomqvist

Paul.Blomqvist@mep.ki.se

Received 18 October 1999 and in final form

20 June 2000

Accepted 7 July 2000

\begin{abstract}
Objectives-Brain tumours cause considerable concern due to a high mortality and there are increasing efforts to provide adequate care, sometimes outside hospitals. Health care utilisation, direct costs of care, and the indirect social cost of morbidity and early mortality caused by brain tumours in Sweden in the year 1996 was analysed.

Methods-Quantification of ambulatory care, care in hospital, long term and palliative/terminal care, drug consumption, temporary as well as long term morbidity, and mortality from comprehensive national data sources. Direct costs were calculated using 1996 charges. Indirect costs were calculated by sex and age specific salaries. A sensitivity analysis considered the impact of alternative estimates of each item.

Results-Indirect costs were $75 \%$ of the total and were caused mainly by early mortality. Direct costs were predominantly for care in hospital, long term care, and home health care. Among direct costs, astrocytomas III-IV and meningiomas accounted for $42 \%$ and $30 \%$ respectively.

Conclusions-The cost of illness from brain tumours reflects the characteristics of these malignancies. Despite their low incidence rate, the economic impact caused by high mortality among young persons is a predominant trait. Costs of acute hospital care and also long term care and home care are considerable. (F Neurol Neurosurg Psychiatry 2000;69:792-798)
\end{abstract}

Keywords: brain neoplasms; cost of illness; Sweden

Each year in Sweden, primary brain tumours account for $3 \%$ of the tumour incidence. ${ }^{1}$ The diagnostic investigation and treatment for these patients is regionalised to six university hospitals, providing comprehensive assessment of each patient by specialists in neurology, neurosurgery, oncology, and neuroradiology.

The prognosis depends mainly on age at diagnosis and the histological type of the tumour with crude absolute survival during the first year after diagnosis ranging from $70 \%$ for type II astrocytomas, $45 \%-60 \%$ for type III astrocytomas, and $20 \%-27 \%$ for glioblastomas. Meningiomas have a crude survival for the first year of well above $90 \%$. Over the years, the prognosis for brain tumours has improved slightly. ${ }^{2-10}$

When assessing healthcare use and the costs of primary brain tumours at the national level, all tumour subtypes and grades need to be included, as brain metastases may mimic primary brain tumours.

Treatment varies according to histological type, patient age, and disability ${ }^{11-13}$ After initial therapy, the need of health care varies considerably depending on the development of the disease.

To our knowledge, health care utilisation and costs of brain tumours have only been studied among selected subgroups of patients, and mainly for new types of treatment. ${ }^{14-34}$ Many studies have been based on case series, typically from one local hospital. Cost analyses have included only direct hospital costs or direct homecare costs. In cost effectiveness analyses, effect data have been summarised from the literature whereas costs have been taken from hospital charges. Efforts to improve economic analyses of patients with cancer by including costs to society and quality of life measures are discussed, but remain to be presented. ${ }^{34-39} \mathrm{We}$ have not found any comprehensive analyses of healthcare use or costs of brain tumours at a national level. Cost of illness studies aim to estimate the burden on society caused by a disease. They include direct medical costs and indirect costs caused by absence from work or premature mortality. ${ }^{40}$

The aim of this study was to describe healthcare utilisation, direct costs of care, and the indirect societal costs of morbidity and early mortality caused by brain tumours in Sweden during the year 1996 .

\section{Material and methods}

SETTING

Sweden (population 8.8 million) has a public healthcare system, based on county councils. Health care is financed mainly by county taxes and both hospitals and primary healthcare centres have defined primary catchment areas. Drug costs, sickness leave compensations, and early retirement pensions are covered by national social security programmes. The private health care sector is small.

\section{MATERIAL}

Incidence of primary brain tumours and mortality data as well as healthcare use were obtained by selecting statistics from different sources. International classification of diseases (ICD9) codes 191, 192 A, B (malignant brain tumours), 225 (benign brain tumours), and 237 A, B, F, G , X, 239 G (tumours of unknown type in the nervous system) were used. For sources using ICD10, diagnoses C70, C71, C72 (malignant brain tumours), D32, D33 (benign brain tumours), and D42, D43 (brain tumours of unknown origin) were selected.

In Sweden, all intracranial primary tumours are reported to six regional centres of oncology and compiled in the national tumour registry. 
Pituitary gland tumours are classified as endocrine tumours and were not included. About $90 \%$ of all incident cases are confirmed histologically. ${ }^{1}$ The histological type of the brain tumour is recorded regionally but not reported in the year book on Cancer Incidence in Sweden. We used data from the regional centre of oncology of the Western Health Care Region (population 1.6 million) to assess the distribution of histological subtypes. ${ }^{11}$

To quantify short term hospital care, we used data from the National Inpatient Register, Centre for Epidemiology, National Board of Health and Welfare. All admissions in 1996 with brain tumours as primary or secondary diagnosis were selected, including the patients' sex, age, operations, or major procedures performed. Nursing home care was assessed from the inpatient registry and the literature. Ambulatory care at hospitals was assessed by 1996 and 1997 statistics from all four hospitals in one county council (population 448 000). Visits in primary health care were obtained from a primary healthcare database. ${ }^{41}$ The National Diagnosis Therapy sample survey, covering all ambulatory health care in Sweden since 1978, was also explored. ${ }^{42}$ Drug use was based on clinical guidelines.

Statistics of episodes of sickness leave were obtained from a 1990 national sample survey, performed by the National Social Insurance Board. ${ }^{43}$ Data were corroborated by comparisons with the Swedish Cancer Registry, the Swedish Death Register, and the National Inpatient Register. ${ }^{44}$

Data on permanent disability were collected from statistics of early retirement pensions 1996 and 1997, and all prevalent cases receiving compensation in 1996 from the National Social Insurance Board. ${ }^{45}$ Data were analysed by diagnosis, sex, and degree of compensation.

Mortality was assessed by analysing data from brain tumours as the underlying cause of death in the Swedish Death Registry 1996. ${ }^{44}$ For patients with brain tumours admitted to hospitals during 1996, causes and dates of death were linked from the same source.

The distribution of direct costs among tumour subtypes was estimated from information on utilisation of diagnostic radiology (CT and MRI), major surgery, radiation therapy, and cytostatics for 136 patients with verified diagnoses at the Sahlgrenska University Hospital, 1996. Costs by subtypes were computed using charges. ${ }^{47}$ The distribution was then applied to the national direct costs.

To calculate the indirect costs by tumour subtype, detailed data on sickness leave episodes, early retirements, and mortality are needed. This information is not available for 1996.

METHODS

All data were corroborated from other sources whenever available, tabulated, and also computed by 100000 population. The impact on total costs of the uncertainty of estimates was considered in a sensitivity analysis.

The economic analysis was performed by the cost of illness approach. ${ }^{48}{ }^{49}$ Briefly, this method aims at calculating the magnitude and mix of different types of costs caused by a disease to society. Firstly, direct costs of all types of healthcare utilisation were calculated by quantifying each type of care. Costs were calculated by applying charges from a national survey (appendix)..$^{50}$

Costs outside the healthcare sector to family members, relatives and friends, or need of additional support of home services may be considerable. ${ }^{33}$ It was not possible to quantify these items reliably.

Indirect societal costs of the disease were computed by analysing the time lost due to temporary and permanent morbidity as well as premature mortality. The time lost was then valued by sex and age specific salaries (human capital method), obtained from national income statistics, including a $36.4 \%$ mark up to cover employers' costs. ${ }^{51}$ Only time lost before 65 years of age (age of old age pension) was considered. We did not consider future increases of productivity in future salaries. Costs of future life-years of lost production were discounted to 1996 at a 5\% interest rate.

Cost of illness analyses may use a prevalence approach to compute the costs. Based on cross sectional data, all consequences of the disease are then included during the baseline year. ${ }^{48}$ Future consequences of premature mortality may then also be included and brought to the baseline year. Alternatively, incident cases may be monitored over time, data accumulated, and the costs calculated. As national annual data on all cases were available for most major items, we used the prevalence approach.

All costs were expressed in Swedish Crowns (SEK) and subsequently converted to US $\$$ at the 1996 exchange rate ( 1 US $\$=6.70$ SEK).$^{52}$

\section{Results}

The distribution of all intracranial brain tumours by histological subtypes during two decades is presented in table 1 . The prevalence in Sweden was 3000 persons. ${ }^{1}$

AMBULATORY CARE

The annual number of visits caused by brain tumours (malignant, benign, and unclassified) at hospital outpatient departments were on average 75 visits/100 000/year. The number of visits/person during 1996 and 1997 ranged from 1.4 to 1.7 (table 2).

During a 10 year period, $13 \%$ of the visits were at primary healthcare centres, and the remaining $87 \%$ at hospital clinics. The Diagnosis Therapy Survey 1988-97 yielded too few observations to give stable estimates of the

Table 1 Brain tumours 1971-90: histological subtypes $(n=3691)$

\begin{tabular}{ll}
\hline Type & $\%$ \\
\hline Astrocytoma I and II & 11 \\
Astrocytoma III and IV & 35 \\
Other malignant brain tumours & 4 \\
Benign meningiomas & 27 \\
Other benign brain tumours & 9 \\
Without pathological anatomical diagnosis & 14 \\
& 100 \\
\hline
\end{tabular}


Table 2 Brain tumours 1996: ambulatory care. Visits/100000 and national totals

\begin{tabular}{|c|c|c|c|c|}
\hline & $\begin{array}{l}\text { Visits/ } \\
100000\end{array}$ & $\%$ & $\begin{array}{l}\text { National } \\
\text { total } 1996\end{array}$ & $\begin{array}{l}\text { US\$ } \\
\text { (millions) }\end{array}$ \\
\hline Primary care & 11 & 13 & 1000 & 0.16 \\
\hline Hospital clinics & 75 & 87 & & \\
\hline Internal medicine & & & 4400 & 0.98 \\
\hline Surgery & & & 2200 & 0.58 \\
\hline Total & 86 & 100 & 7600 & 1.72 \\
\hline
\end{tabular}

The distribution between internal medicine (2/3) and surgery $(1 / 3)$ is based on the distribution of admissions.

annual number of consultations. Patients with brain tumours may consult private physicians but there are no national data on this.

To corroborate the estimates of ambulatory care we considered a typical chain of visits. Initially, a patient visits primary care, and is then referred to a neurologist. Diagnostic and perioperative consultations may result in at least five visits for 1100 incident tumour patients, or 5600 visits. About 960 persons receive early retirement pension for brain tumours each year, an additional 1000 patients are younger than 20 years or older than 64 years. These patients need at least one visit a year, which brings a total of 7500 visits a year.

CARE IN HOSPITAL

Admissions of patients with brain tumours accounted for $0.5 \%$ of the 1996 national total. Among these, $42 \%$ of the patients had a primary diagnosis of malignant brain tumour, $21 \%$ benign brain tumour, and $15 \%$ undefined brain tumour. The remaining patients had brain tumours as secondary diagnoses. Each patient was admitted 2.3 times - that is, 3700 persons were admitted, or 42 persons/ 100000 .

The patients were admitted mainly to clinics of internal medicine (34\%), neurology (18\%), and neurosurgery $(21 \%)$. The mean duration of stay was 8.8 days (SD 20.2) (table 3).

An operation or a major procedure was performed during $24 \%$ of the admissions. Most frequent were neurosurgical operations $(19 \%)$ - that is, extirpation of tumours (radical, subtotal or partial), followed by stereotactic biopsies.

Most patients (78\%) were admitted directly from their homes, and $21 \%$ from other clinics or hospitals. Two thirds of those admitted during 1996 were discharged to their own homes, and $25 \%$ to other clinics or hospitals.

LONG TERM CARE, PALLIATIVE/TERMINAL CARE In 1996, there were 680 discharges from long term clinics, with a median duration of stay of 18.0 days (quartile range 26.0).

Table 3 Brain tumours 1996. Hospital admissions

\begin{tabular}{lllllll}
\hline Clinic & Admissions & $\%$ & Days & $\%$ & $\begin{array}{l}\text { US } \$ \\
\text { (millions) }\end{array}$ & $\begin{array}{l}\text { Costs/ } \\
100000\end{array}$ \\
\hline Internal medicine & 2714 & 34 & 27354 & 40 & 12.1 & \\
Paediatrics & 1061 & 14 & 3380 & 5 & 2.5 & \\
Neurology & 1443 & 18 & 13750 & 20 & 8.1 & \\
Neurosurgery & 1659 & 21 & 11867 & 17 & 7.8 & \\
Ear, nose, and throat & 149 & 2 & 704 & 1 & 0.6 & \\
Other surgery & 423 & 5 & 2741 & 4 & 1.8 & \\
Oncology & 361 & 5 & 3434 & 5 & 2.1 & \\
Other & 80 & 1 & 4643 & 7 & 1.8 & \multirow{2}{*}{0.42} \\
Total & 7890 & 100 & 67873 & 100 & 36.8 & \\
\hline
\end{tabular}

Table 4 Brain tumours 1996: long term care and home health care

\begin{tabular}{llll}
\hline Type of care & $\begin{array}{l}\text { Patient } \\
\text { days }\end{array}$ & $\begin{array}{l}\text { US\$ } \\
\text { (millions) }\end{array}$ & $\begin{array}{l}\text { Cost/ } \\
100000\end{array}$ \\
\hline Long term care & 20400 & 7.0 & 0.08 \\
Home health care & 27100 & 2.9 & 0.03 \\
Total & 47500 & 9.9 & 0.11 \\
\hline
\end{tabular}

About 60 units provided home health care or specialised palliative home care. ${ }^{53}$ It is estimated that during 1996, 150 persons received on average 6 months of terminal care outside hospitals. Use of long term care and home health care for patients with brain tumours is summarised in table 4 .

DRUG CONSUMPTION

The most common drugs prescribed for patients with brain tumours in ambulatory care were corticosteroids (betametazone), antiepileptic drugs (carbamazepine), antiulcer medication (omeprazol), and analgesics (dextropropoxiphene). Based on clinical guidelines the average daily dosage of these drugs was estimated to be $1 \mathrm{mg}$ betametazone, $800 \mathrm{mg}$ carbamazepine, $20 \mathrm{mg}$ omeprazol, and $195 \mathrm{mg}$ dextropropoxiphene (table 5).

Drug use by patients admitted to hospitals is not available. These costs are, however, seldom specified but included in the cost/bed-day or cost/admission.

TEMPORARY MORBIDITY

The number of sickness leave episodes for malignant brain tumours reported in a national survey 1990 was 200 for men and women. The duration was very long, and the number of compensated days was 61000 . In addition, an equal number of sick leave episodes and days is estimated to have been compensated for, for patients with benign and undefined tumours, or a total of 120000 days with $53 \%$ attributed to women (table 6).

LONG TERM MORBIDITY

In 1996, 146 men and women were granted early retirement pensions for brain tumours, $(0.4 \%$ of annual total), or 1.7 per 100000 population. Almost two thirds of these had malignant brain tumours and $73 \%$ received full compensation. The median age was 47 years for both men and women. Provided that these persons would survive until the age of 65 (age of ordinary old age pensions), 2100 productive life years would be lost.

Table 5 Brain tumours 1996: drug use in ambulatory care

\begin{tabular}{lll}
\hline Type & US \$ (millions) & /100000 \\
\hline Corticosteroids & 0.2 & \\
Antiepileptics & 0.5 & \\
Analgesics & 0.4 & \\
Antiulcer medication & 2.2 & 0.04 \\
Total & 3.3 & 0.3 \\
\hline
\end{tabular}

Table 6 Brain tumours 1996: sickness leave

\begin{tabular}{llll}
\hline & Days compensated & Days/100000 & US\$ (millions) \\
\hline Males & 57000 & 648 & 6.5 \\
Females & 63000 & 716 & 5.1 \\
Total & 120000 & 1364 & 11.6 \\
\hline
\end{tabular}


Table 8 Brain tumours 1996: mortality. Cost of life-years lost

\begin{tabular}{|c|c|c|c|c|c|c|c|c|c|c|c|}
\hline \multirow[b]{2}{*}{ Type } & \multicolumn{10}{|l|}{ Age } & \multirow[b]{2}{*}{ Total } \\
\hline & $0-19$ & -24 & -29 & -34 & -39 & -44 & -49 & -54 & -59 & -64 & \\
\hline \multicolumn{12}{|c|}{ Productive life-years lost: } \\
\hline Males & 644.0 & 42.5 & 187.5 & 292.5 & 357.5 & 427.5 & 420.0 & 375.0 & 210.0 & 80.0 & 3036.5 \\
\hline Females & 368.0 & 127.5 & 112.5 & 97.5 & 55.0 & 247.5 & 315.0 & 237.5 & 180.0 & 100.0 & 1840.5 \\
\hline Total & 1012.0 & 170.0 & 300.0 & 390.0 & 412.5 & 675.0 & 735.0 & 612.5 & 390.0 & 180.0 & 4877.0 \\
\hline \multicolumn{12}{|c|}{ Costs US\$ (millions): } \\
\hline Males & 8.1 & 0.7 & 3.6 & 6.4 & 8.8 & 11.8 & 12.9 & 12.6 & 7.6 & 3.3 & 75.8 \\
\hline Females & 3.4 & 1.5 & 1.6 & 1.5 & 1.0 & 4.9 & 6.9 & 5.7 & 4.6 & 2.8 & 33.9 \\
\hline Total & 11.5 & 2.2 & 5.2 & 7.9 & 9.8 & 16.7 & 19.8 & 18.3 & 12.2 & 6.1 & 109.7 \\
\hline
\end{tabular}

Life-years lost from death through 64 years. Undiscounted.

Future incomes discounted at $5 \%$ interest rate.

Among persons already receiving early retirement pensions in 1996, 972 persons $(0.2 \%$ of a total of 403800$)$ had brain tumour as an underlying diagnosis $(11.0 / 100000$, table 7 ). Of these, $72 \%$ received full compensation, and $49 \%$ had malignant brain tumours.

Life-years lost was calculated from the prevalent group, stratified by sex and age, and recalculated to full time work equivalents.

MORTALITY

In 1996,736 persons $(0.8 \%)$ had brain tumours as an underlying cause of death $(8 / 100$ 000 population). Of these, $74 \%$ had malignant tumours, $18 \%$ histologically undefined brain tumours, and the remainding $8 \%$, benign brain tumours. For malignant brain tumours, $48 \%$ of those dying were 64 or younger. Among those having benign or histologically undefined brain tumours, less than a fifth were younger than 65 . The total productive life-years lost and the costs are presented in table 8 .

To validate this, we also assessed our data on the 3700 persons admitted during 1996. The mortality among these patients was high, and $25.8 \%$ died during the same year. The most common cause of death was brain tumours $(62.3 \%)$, followed by other tumours $(24.8 \%)$ notably, lung cancer. Among those who were admitted and then died, most $(70 \%)$ died in a hospital.

\section{DIRECT COSTS}

The direct costs of health care for brain tumours in Sweden were 51.7 million US\$, or 5.9 million US $\$ /$ million population (table 9 ). Of these costs, $71 \%$ were for short term care in hospital. Admissions at clinics of neurosurgery and internal medicine accounted for about a fifth of these. Long term care, including hospital based home care, accounted for $19 \%$ of the total. Ambulatory care was only $3 \%$ of the total; this was mainly visits to hospital specialists.

INDIRECT COSTS

The costs of temporary morbidity were 11.6 million US $\$$, or 1.3 million US $\$ /$ million population (table 9). The numbers of compensated

Table 7 Brain tumours 1996: early retirement pensions

\begin{tabular}{lllllll}
\hline Tumour type & Males & FTE & $\begin{array}{l}\text { Indirect costs } \\
\text { US\$ (millions) }\end{array}$ & Females & FTE & $\begin{array}{l}\text { Indirect costs } \\
\text { US\$ (millions) }\end{array}$ \\
\hline Malignant & 222 & 189 & & 258 & 219 & \\
Benign & 131 & 113 & & 246 & 213 & \\
Not defined & 56 & 49 & & 59 & 50 & \\
Total & 409 & 351 & 14.5 & 563 & 482 & 14.3 \\
\hline
\end{tabular}

FTE=Full time equivalent. days were fewer for men than for women but the costs were higher, reflecting the fact that male salaries were higher. Early retirement pensions granted in 1996 and earlier caused costs of lost production of 28.8 million US $\$$ or 3.3 million US $\$ /$ million population. Mortality among those younger than 65 took the largest part of the costs with 109.7 million US $\$$ or 12.5 million US $\$ /$ million. The total indirect costs were 17.1 million US $\$ /$ million population.

TOTAL COSTS

The total cost of illness in 1996 was 201.8 million US $\$$ or 22.9 million US $\$ /$ million (table 9 ). Indirect costs were $74 \%$, and $73 \%$ of these were in turn due to early mortality. The direct cost constituted $26 \%$, chiefly for care in hospital and long term care.

DIRECT COSTS BY TUMOUR SUBTYPE

The accumulated direct costs by tumour subtype are summarised in table 10 . The total costs/patient in our subset was 14.460 US $\$$, with $6.4 \%$ attributed to diagnostic efforts, and the remainder for therapy. In 1996, 79.9\% of therapy costs were attributed to surgical wards, $19.2 \%$ to radiology therapy, and $0.9 \%$ to the use of cytostatics. Astrocytomas III-IV took the largest part, followed by meningiomas. The distribution among tumour subtypes of the

Table 9 Brain tumours 1996: total cost 1996

\begin{tabular}{llll}
\hline & $\begin{array}{l}\text { US\$ } \\
\text { (millions) }\end{array}$ & $\%$ & $\%$ \\
\hline Direct costs: & & & \\
$\quad$ Ambulatory care & 1.7 & 3.3 & \\
$\quad$ Hospital care & 36.8 & 71.1 & \\
$\quad$ Long term and home care & 9.9 & 19.1 & \\
$\quad$ Drugs & 3.3 & 6.4 & \\
Indirect costs: & 51.7 & 100.0 & 25.6 \\
$\quad$ Sickness leave & 11.6 & 7.7 & \\
$\quad$ Early retirement & 28.8 & 19.2 & \\
$\quad$ Mortality & 109.7 & 73.1 & \\
& 150.1 & 100.0 & 74.4 \\
Total costs & 201.8 & & 100.0 \\
\hline
\end{tabular}

Table 10 Brain tumours 1996: direct costs by tumour subtype

\begin{tabular}{lll}
\hline Type & US\$ (millions) & $\%$ \\
\hline Astrocytomas I-II & 6.7 & 13 \\
Astrocytomas III-IV & 21.7 & 42 \\
Lymphomas & 1.6 & 3 \\
Meningiomas & 15.5 & 30 \\
Metastases & 6.2 & 12 \\
& 51.7 & 100.0 \\
\hline
\end{tabular}


costs of diagnostic investigation and therapy was very similar to the incidence.

SENSITIVITY ANALYSIS

If our estimate of annual volumes of visits to physicians would have been $20 \%$ higher or alternatively, lower, the direct costs would change by 0.6 percentage points. The total costs would only change by 0.2 percentage points.

The volumes of hospital admissions for primary brain cancer were based on comprehensive national data. It might, however, be worthwhile to perform these analyses by only including admissions for patients with brain cancer as a primary diagnosis. The number of admissions would then decrease by 21.8 percentage points. With a constant distribution of bed days among clinics, the direct costs would decrease by 15.5 percentage points and the total costs by 4.0 percentage points.

Long term care information was taken from the national inpatient registry, and we consider it to be reliable. If only patients with a primary diagnoses of brain cancers are considered, $68.2 \%$ of the admissions would be included. The costs of long term care would then decrease from 7.0 million US $\$$ to 4.8 million US\$. The total costs of long term care and home health care combined would decrease by 22.2 percentage points. The direct costs would decrease by 4.3 percentage points and the total costs by 1.5 percentage points.

Drug use was estimated from clinical guidelines but the exact number of patients receiving drug treatment outside hospitals during a year is not known. We estimated that 2550 patients received drug treatment. The duration of treatment was estimated as 6 months for the 550 incident cases, and 12 months for 2000 prevalent cases. If the number of patients changed by $20 \%$, direct costs would change by 1.4 percentage points and the total costs by only 0.3 percentage points. In our main alternative, all patients received antiulcer medication to prevent possible adverse reactions of corticosteroids. The cost of antiulcer medication was $65.5 \%$ of the total annual drug cost/patient. Apparently, any reduction of this proportion or its costs would reduce total drug costs considerably.

Sickness leave days were estimated from a sample survey and compared with bed days in inpatient care. There are no other contemporary sources available to corroborate this. If the number of days compensated is either $20 \%$ lower or higher, the corresponding indirect costs would change by 1.5 percentage points and the total costs by 1.1 percentage points.

We calculated the indirect costs of early retirement pensions, based on prevalent cases. This group actually comprises patients with incident tumours granted a pension during 1996 and patients who received pensions earlier. This group is also diminished by mortality, both from brain tumours and other causes.

In cost of illness studies, the costs of permanent morbidity are sometimes calculated from incidence data due to lack of data on prevalence. Statistics were also available by sex, age, and grade of compensation for all new early retirement pensions in 1996. Provided that they would have lived until 65 (age of ordinary old age pension), a future 2106 productive years would have been lost, or 14.4 years/person. Given the high mortality among patients with primary brain tumours, this is most likely a high estimate. As we do not have any individual data on mortality among patients with primary brain tumours with an early retirement pension, we instead used data on all prevalent cases.

We used national statistics on sex and age specific causes of death 1996. Missing data on causes of death that year were $0.8 \%{ }^{44}$ It is, however, unlikely that this would be selective for patients with brain tumours and have any major impact on our calculations.

The consequences of mortality may be considered only during the baseline year. Confining the indirect cost of mortality to the year 1996 only would have brought a cost to society of 10.5 million US $\$$, or $9.6 \%$ compared with the total accumulated and discounted cost of mortality.

The distribution of direct costs by tumour subtypes was based on detailed data from one regional database 1996 with both local as well referred patients. As not all patients may be referred for evaluation due to advanced disease, these data may underestimate tumours with high mortality or severity. The distribution of direct costs between surgery, radiation therapy, and cytostatics has also changed after 1996, due to the development of care.

All costs were originally calculated in Swedish Crowns (SEK) and then recalculated to US $\$$ by the average 1996 exchange rate. This rate varied considerably during the 1990s, implying that another base year would have brought different costs. However, the distribution between cost items would have been similar.

\section{Discussion}

Our main finding was that the costs of primary brain tumours in Sweden 1996 were predominantly indirect costs, caused by early mortality, early retirement, and sickness leave. Together, these consequences caused $75 \%$ of the total, with direct costs of health care being only $25 \%$. The largest portion of these, about $70 \%$, came from care in hospital while long term care and home health care comprised the remainder.

Considering the reliability of our data sources in a sensitivity analysis, the largest costs items were care in hospital and mortality. Both of these were based on comprehensive national statistics, with a high precision and validity.

We were able to assess that the astrocytomas III-IV and other malignant types were behind more than half of the direct costs. This is a consequence of a high incidence rate, disease severity, and high mortality. We have no original data for 1996 on morbidity or mortality by tumour subtypes, necessary to estimate indirect costs. The high mortality among patients with astrocytomas III and IV 
implies, however, that they would have a large proportion of these costs.

On the national level, the direct costs of brain tumours were $0.3 \%$ of the direct cost and $0.5 \%$ of the total indirect costs in $1996 . .^{54}$ Comparing the costs of brain tumours to costs of the tumour disease group indicates that brain tumours accounted for $5.4 \%$ of the direct costs and $9.8 \%$ of the indirect costs. ${ }^{55}$

Mortality among patients with brain tumours causes a substantial economic impact to society, and changes in survival have the greatest influence on the total costs. This is mainly a consequence of two factors. One is a considerable mortality among young and middle aged persons. It is also a consequence of a sex difference of mortality. In 1996, the number of men and women dying of primary brain cancer was almost equal but $48 \%$ of the men died before 65 years of age, compared with a third of the women. Because the indirect costs are calculated using sex and age specific salaries, a high proportion of men dying early will have a considerable impact on the total costs.

The direct costs were predominantly for care in hospital. In addition, efforts and time spent by families, relatives, and friends are indeed important for the care of these patients. However, it was not possible to quantify the extent of this, and thereby impossible to calculate the economic consequences. Some patients reside permanently in nursing homes, due to persistent impairment. Also, for this group there were no comprehensive statistics available. Therefore we may have underestimated these costs.

The strength of our study is that we have been able to use national cross sectional data. Also, the main cost components, care in hospital as well as loss of productive life-years due to premature mortality, were based on complete national data sources. The charges we used when costing in hospital services were obtained from a recent national survey. Salaries, used to value the time lost, were retrieved from the national statistics, based on all income tax returns in Sweden.

A caveat of our study is that original data on ambulatory care as well as drug use outside hospitals were scarce. However, the proportion of these items, even after making allovances for this uncertainty, was only moderate. Our calculations of the costs by tumour subtype were based on regional data as no national data were available.

The cost of illness method has been criticised as it does not compare alternatives. Thereby, it does not immediately enhance our ability to reach cost effective decisions of the choice between methods in diagnostics or treatment. Also, the method has several characteristics developed over time but with weak foundation in economic theory. ${ }^{5677}$ The inclusion of indirect costs has also been questioned..$^{58}$ It is worth considering again that the purpose of the method is to calculate the magnitude and mix of the total economic consequences of a disease, caused by morbidity as well as mortality, during one time period, and in one defined geographical area. Thereby, these analyses bring information appreciated by decision makers, executives, and administrators, as they provide an overview of the total economic impact of a disease. These analyses thus provide a framework, and point of reference for more detailed studies. ${ }^{48} 49$ They are not an alternative to cost effectiveness or cost utility analyses, but a complement.

In conclusion, our economic analysis of the cost of illness of brain tumours reflects the characteristics of these malignancies. Despite its low incidence rate, the economic impact caused by a high mortality rate among young persons, is a dominant trait. In addition, the costs of hospital care, but also long term care and home care, are considerable.

We thank Ingela Funegard for providing data from the Brain Tumour Database, Western Health Care Region, Sahlgrenska University Hospital, Gothenburg. This study was partly supported by a grant from the Integrated Therapeutics Group, Schering Plough Corporation.

\section{Appendix}

\begin{tabular}{ll}
\hline $\begin{array}{l}\text { Costs 1996 US } \$ \\
\text { Consultations: }\end{array}$ & \\
$\quad$ Primary care & \\
$\quad$ Hospital clinics & \\
$\quad$ Internal medicine & \\
$\quad$ Surgery & 222 \\
Admissions: & 261 \\
Clinic & \\
Internal medicine & Cost/day \\
Paediatrics & 443 \\
Neurology & 746 \\
Neurosurgery & 585 \\
Ear, nose, and throat & 660 \\
Other surgery & 816 \\
Oncology & 648 \\
Other & 622 \\
Long term hospital care & 443 \\
Home health care & 343 \\
Drug use/patient and year & $106^{\star}$ \\
Corticosteroids & Costs \\
Antiepileptics & 91 \\
Analgesics & 196 \\
Antiulcer medication & 160 \\
Total & 852 \\
Average 1996 salary & 1299 \\
Age 20-64 (incl social costs 36.4\%) & \\
$\quad$ Men & \\
$\quad$ Women & 41343 \\
& 29702
\end{tabular}

^SPRI Survey 1999, to be published.

1 Cancer Incidence in Sweden 1997. Statistics-Health and Disases. Stockholm: National Board of Health and Welfare, Centre for Epidemiology, 1999;386-9.

2 Ericsson J, Stenbeck M. Cancer survival in Sweden in 1961-1991. Eye, brain and nervous system. Acta Oncol 1995;34(suppl 4):83-93.

3 Modan B, Wagener DK, Feldman JJ, et al. Increased mortality from brain tumours: a combined outcome of
diagnostic technology and change of attitude toward the elderly. Am ₹ Epidemiol 1992;135:1349-57.

4 Devaux BC, O'Fallon JR, Kelly PJ. Resection, biopsy, and survival in malignant glial neoplasms. A retrospective study survival in malignant glial neoplasms. A retrospective study
of clinical parameters, therapy, and outcome. $\mathcal{F}$ Neurosurg
$1993 ; 78: 767-75$

5 Kallio $M$. Therapy and survival of adult patients with intracranial glioma in a defined population. Acta Neurol Scand 1990:81:541-46.

6 Sanat M, Crosignani P, Bordo BM, et al. Incidence and survival of brain tumors: a population-based study. Tumori $1988 ; 74: 243-52$

7 Preston-Martin S, Staples M, Farrugia H, et al. Primary tumors of the brain, cranial nerves and cranial meninges in Victoria, Australia, 1982-90: patterns of incidence and survival. Neuroepidemiology 1993;12:270-9.

8 Surawicz TA, Davis F, Freels S, et al. Brain tumor survival: results from the National Cancer Data Base. F Neurooncol 1998;40:151-60.

9 Davis FG, Freels S, Grutsch J, et al. Survival rates in patients with primary malignant brain tumors stratified by patient
age and tumor histological type: an analysis based on surveillance, epidemiology, and end results (SEER) data, surveillance, epidemiology, and end

10 Shugg D, Allen BJ, Blizzard L, et al. Brain cancer incidence, mortality and case survival: observations from two Austral ian cancer registries. Int $\mathcal{F}$ Cancer 1994;59:765-70. 
11 Brain tumours, diagnostics, treatment, and supportive care of adult patients. Regional health care program 1994. Gothenburg: Regional Center of Oncology, Western Health Care Region, 1994. (ISSN 1100-1070.)

12 Becker LA, Green IA Beaufait D, et al. Detection of intracranial tumours, subarachnoid hemorrhages, and subdural hematomas in primary care patients: a report from ASPN, part 2. F Fam Pract 1993;37:135-41.

13 Robbins SL. Robbins' pathologic basis of disease, 4 th ed. In: Cotran RS, Kumar V, Robbins SL, eds. Pathologic basis of disease. Philadelphia: W B Saunders, 1989.

14 National Cancer Institute. Adult brain tumour. PDQ. Treatment. Health professionals. http://cancernet.nci.nih.gov.

15 Stiles CD. Cancer of the central nervous system. Review of an AACR special conference in cancer research with the joint section on tumours of the AANS/CNS (San Diego, CA, June $7-11,1997)$. Meeting report. Biochim Biophys Acta 1998; 1377:R1-10.

16 Layon AJ, George BE, Hamby B, et al. Do elderly patients overutilize healthcare resources and benefit less from them than younger patients? A study of patients who underwent
craniotomy for treatment of neoplasm. Crit Care Med craniotomy for

17 Epstein ME, Lindquist C. Cost accounting the gamma knife. Proceedings of the 1992 Meeting of the Leksell Gamma Knife Society, Buenos Aires, Argentina. Stereotact Funct Neurosurg 1993;61(suppl 1):6-10

18 Ragnarson Tennvall G, Karlsson G. Cancer treatment in Sweden: costs of drugs, inpatient and outpatient care from 1985 to 1996 and cost effectiveness of new drugs. Acto Oncol 1998;37:447-53.

19 Penar PL. Cost and outcome analysis. Neurosurg Clin N Am 1996;7:547-58.

20 Silverstein MD, Cascino TL, Harmsen WS. High-grade astrocytomas: resource use, clinical outcomes, and cost of care. Mayo Clin Proc 1996;71:936-44.

21 Rutigliano MJ, Lunsford LD, Kondziolka D, et al. The cost effectiveness of stereotactic radiosurgery versus surgical resection in the treatment of solitary metastatic brain resection in the treatment of solitary

22 Polinsky MN, Geer CP, Ross DA. Stereotaxy reduces cost of brain tumour resection. Surg Neurol 1997;48:542-51.

23 Mehta M, Noyes W, Craig B, et al. A cost-effectiveness and cost-utility analysis of radiosurgery $v$ resection for singlebrain metastases. Int $\mathcal{F}$ Radiation Oncol Biol Phys 1997;39 445-54.

24 Rutigliano MJ. Cost and survival analysis of metastatic cerebral tumours treated by resection and radiation. Correspondence. Neurosurgery 1994;35:797-8.

25 Lunsford LD. Cost of surgical treatment of metastases [comments]. Neurosurgery 1994;34:893-94.

26 Penar PL, Wilson JT. Cost and survival analysis of metastatic cerebral tumours treated by resection and radiation. Neurosurgery 1994;34:888-93.

27 Pickard JD, Bailey S, Sanderson H, et al. Steps towards cost-benefit analysis of regional neurosurgical care. $B M \mathcal{F}$ 1990;301:629-35.

28 Beck-Friis B, Strang P. The family in hospital-based home care with special reference to terminally ill cancer patients. care with special reference to

29 Beck-Friis B, Strang P. The organization of hospital-based home care for terminally ill cancer patients: the Motala model. Palliative Med 1993;7:93-100.

30 Beck-Friis B, Norberg H, Strang P. Cost analysis and ethical aspects of hospital-based home-care for terminal cance patients. Scand F Prim Health Care 1991;9:259-64.

31 McCusker J, Stoddard AM. Effects of an expanding home care program for the terminally III. Med Care 1987;25. 373-85.

32 Hjortsberg C, Svarvar P. Cost comparison of advanced home health care and inhospital care for terminal cancer patients. IHE Working paper 1999:2. (ISSN 1100-4657, 1999.) (In Swedish.)
33 Stommel M, Given CW, Given BA. The cost of cancer home care to families. Cancer 1993;71:1867-74.

Gralysis of terminal cancer care in home hospice patients and controls. Fournal of Chronic Diseases 1987;40:801-10.

35 Choucair AK, Scott D, Urtasun R, et al. Quality of life and neuropsychological evaluation for patients with malignant astrocytomas: RTOG 91-14. Int $\mathcal{F}$ Radiation Oncol Biol Phys 1997;38:9-20.

36 Neymark N, Kiebert W, Torfs K, et al. Methodological and statistical issues of quality of life (Qol) and economic evaluation in cancer clinical trial: report of a workshop. Eur 7 Cancer 1998;34:1317-33.

37 Goddard M, Drummond M. The economic evaluation of cancer treatments and programmes. Eur F Cancer 1991;27: 1191-6.

38 Drummond MF. Economics in cancer care. Eur $\mathcal{F}$ Cancer 1995;31A:1387.

39 Fitzpatrick R, Davies L. Health economics and quality of life in cancer trials: report based on a UKCCCR workshop. $\mathrm{Br}$ 7 Cancer 1998;77:1543-8.

40 Kobelt G. Health economics. An introduction to economic evaluation. London UK: Office of Health Economics, 1996.

1 Svärdsudd K, Korpela M. Diagnosredovisning för läkarbesök år 1996 vid vårdcentralen $i$ Tierp. (Diagnoses in Primary Care 1996, Department of Public Health, Tierp Primary Care Center. Report.) Uppsala, Sweden: Uppsala University, 1997

42 Apoteksbolaget, Stockholm. Svensk läkemedelsstatistik 1996 (Statistical Yearbook of Drugs 1996). Stockholm: 1997.

43 National Social Insurance Board. Sjukfrånvarons diagnoser och avslutningsanledningar 1990. (Diagnoses at sick leave episodes, 1990. Report) Stockholm: National Social Insurance Board 1996:3 (ISSN 0283-0965)

44 Dödsorsaker 1996. (Causes of death 1996.) Stockholm: The National Board of Health and Welfare, Centre for Epidemiology, 1998 (ISBN 91-7201-243-9).

45 Nybeviliade förtidspensioner/sjukbidrag 1996. (Early retirement pensions in 1996. Report) Stockholm: National Social Insurpensions in 1996. Rep
ance Board, 1998.

46 Early retirement pensions in Sweden 1996. Report. Stockholm: National Social Insurance Board, 1997 (In Swedish).

47 Prislista 1996. Sydöstra sjukvårdsregionen. (Pricelist 1996), Linköping, Sweden: South Eastern Health Care Region 1995 (In Swedish)

48 Hodgson TA. Cost of illness in cost-effectiveness analysis. Pharmacoeconomics 1994;6:536-52.

49 Rice DP. Cost-of-illness studies: fact or fiction? Lancet 1994;344:1519-20.

50 Kostnader per intagen patient, vårddag och läkarbesök mm. 1996. (Cost per patient, bed day, and visit 1996. Report.) Stockholm: Federation of county councils, 1998.

51 Inkomster, skatter och bidrag. Statistiska meddelanden. (Salaries 1996). National Income Statistics. Statistics Sweden. Örebro, 1997.

52 Average exchange rates 1994-8. Stockholm: The Swedish Central Bank, 1998.

53 Bäsén A. Palliative care. Dagens Medicin 1999;18:14.

54 The National Board of Health and Welfare. Statistics: Hälsooch sjukvårdsstatistisk årsbok 1998. (Yearbook of Health and Medical Care 1998.) Stockholm: The National Board of Health and Welfare, 1998 (ISBN 91-7201-307-9.)

55 The National Board of Health and Welfare. Hälso-och sjukvardsstatistisk årsbok 1995. (Yearbook of Health and Medical Care 1995). Stockholm: The National Board of Health and Welfare, 1995. (ISBN 91-7201-059-2.)

56 Drummond MF.Cost-of-illness studies. A major headache? Pharmacoeconomics 1992;2:1-4.

57 Shiell A, Gerard K, Donaldson C. Cost-of-illness studies: an aid to decision-making? Health Policy 1987;8:317-23.

58 Koopmanschap MA, van Ineveld BM. Towards a new. approach for estimating indirect costs of disease. Soc Sci Med 1992;34:1005-10. 